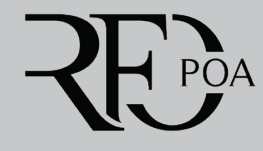

\title{
CuIdAdO EM SAÚdE BUCAL SEM PRECONCEITO: SINGULARIDADES DA COMUNIDADE LGBTI+
}

\author{
Matheus Neves ${ }^{a}$, (D) Jonas Almeida Rodrigues ${ }^{b}$
}

Em um país de dimensões continentais, marcado pela diversidade étnico-cultural e pela flagrante desigualdade socioeconômica, a implementação de um sistema de saúde público e universal constitui tarefa desafiadora, tanto para a gestão dos serviços de saúde, quanto para a assistência e o cuidado à saúde do usuário. Mais além, chama a atenção, no cenário nacional, o incremento das desigualdades em saúde e o aumento da discriminação de populações singulares, dentre elas a comunidade LGBTI+.

Na esteira da conscientização e da necessária implementação de ações para aumentar a visibilidade LGBTI+ no sistema de saúde e, também, nos sistemas socioeconômico e político, a Política Nacional de Saúde Integral de Lésbicas, Gays, Bissexuais, Travestis e Transexuais (PNSILGBT), instituída pela Portaria no 2.836 , de $1^{\circ}$ de dezembro de 2011, é considerada um marco para as políticas públicas de saúde no Brasil e uma sinalização histórica de reconhecimento das demandas desta população1.

Em que pese os dados sejam escassos na literatura odontológica sobre as necessidades de saúde bucal específicas da comunidade LGBTI+, é fato que a equipe de saúde bucal deve prestar cuidados culturalmente competentes para esse público. É provável que o melhor cuidado para esse grupo só possa ser alcançado por meio do atendimento interprofissional, articulado entre toda a equipe de saúde.
Em uma abordagem atual, os profissionais de saúde devem estar interessados em conhecer a orientação sexual dos usuários, a fim de avaliar o risco para o adoecimento; o que, por óbvio, vai além das manifestações bucais decorrentes das doenças sexualmente transmissíveis. Além disso, quando se trata da concepção das Redes de Atenção à Saúde, cabe à equipe articular-se intimamente com a população adstrita, estratificada em subpopulações e organizada em grupos que habitam territórios de vida $^{2,3}$.

O que é de importância prática e essencial, é que os cirurgiões-dentistas precisam ser sensíveis e conhecedores dos conceitos de orientação sexual, identidade de gênero e expressão de gênero ${ }^{4}$, pois a sexualidade tem sido temática central nos mais diversos debates políticos, biomédicos, sociais e antropológicos. O cerne dessas discussões encontra-se nos processos discriminatórios e de exclusão gerados ao longo da história. No campo da saúde não é diferente, sobretudo no que se refere à assistência e ao acesso aos serviços de saúde ${ }^{4}$.

Sabe-se que o preconceito, o estigma por orientação sexual, identidades, expressões de gênero e sexualidade são fatores de vulnerabilidade em saúde, expondo a população LGBTQI+ - na qual incluem-se as pessoas auto-identificadas como queers (Q), as pessoas intersexuais (I) e outras identificações

\footnotetext{
a Professor Adjunto da Faculdade de Odontologia e do Programa de Pós-Graduação em Saúde Coletiva da Universidade Federal do Rio Grande do Sul, Porto Alegre, RS, Brazil.

${ }^{\mathrm{b}}$ Professor Associado da Faculdade de Odontologia e do Programa de Pós-Graduação em Odontologia Universidade Federal do Rio Grande do Sul, Porto Alegre, RS, Brazil. Editor Chefe da Revista da Faculdade de Odontologia de Porto Alegre, RFO-POA.
} 
como, por exemplo, pessoas não-binárias $(+)$ - a agravos decorrentes dos processos discriminatórios e de exclusão social, violando seus direitos humanos, entre os quais o direito à saúde, à dignidade, à não discriminação, à autonomia e ao livre desenvolvimento ${ }^{1}$.

O ponto nevrálgico da Saúde Bucal no Brasil encontra-se no acesso, e vale destacá-lo como princípio essencial para a efetivação do cuidado em saúde. O usuário LGBTI+ pode sofrer discriminações, traduzidas em barreiras no acesso aos serviços de saúde, o que eleva os padrões de vulnerabilidade, fatos que sinalizam a importância de aumentar o uso de tecnologias leves no cuidado da saúde LGBTI $+^{1,2}$.

\section{COMO A EQUIPE DE SAÚdE BUCAL DEVE AGIR?}

Baseado no documento "Nascidos livres e iguais"s, que trata da orientação sexual e da identidade de gênero na Declaração Internacional dos Direitos humanos, a equipe de saúde bucal deve manter em seu processo de trabalho este sumário de 5 passos:

1. PROTEGER as pessoas da violência homofóbica e transfóbica, o que inclui estabelecer estratégias e sistemas eficazes para registrar e denunciar atos de violência motivados pelo ódio.

2. PREVENIR o tratamento cruel, preconceituoso, desumano e degradante de usuários LGBTI+. Para tanto, deve-se fornecer treinamento adequado à equipe de saúde em ações de educação permanente que incluam a LGBTfobia em pauta.

3. ELIMINAR práticas que "criminalizam" a homossexualidade nos serviços de saúde, incluindo todas as condutas que possam constranger os indivíduos com base em sua orientação sexual ou identidade de gênero, como por exemplo o não uso do nome social.

4. GARANTIR o acesso não discriminatório de pessoas LGBTI+ aos serviços de saúde bucal e a toda a Rede de Atenção à Saúde. Cumprindo-se os princípios da universalidade e da equidade do SUS, além de conhecer a PNSILGBT.

5. DEFENDER a liberdade de expressão, a fim de que a equipe de saúde bucal e o serviço de saúde como um todo, tornem-se locus de acolhimento, para a construção de vínculo, cuidado em saúde e proteção social.

Portanto, é preciso avançar na compreensão:

\section{Orientação sexual}

É a capacidade de cada pessoa de ter atração emocional, afetiva ou sexual por indivíduos de gênero diferente, mesmo gênero ou mais de um gênero, assim como ter relações íntimas e sexuais com essas pessoas ${ }^{6}$.

\section{Identidade de gênero}

É a experiência individual do gênero de cada pessoa, que pode ou não corresponder ao sexo atribuído no nascimento, incluindo o senso pessoal do corpo. Refere-se a como a pessoa se identifica e quer ser reconhecida socialmente ${ }^{6}$.

\section{Expressão de gênero}

É a maneira como a pessoa manifesta publicamente, por meio do seu nome, da vestimenta, do corte de cabelo, dos comportamentos, da voz e/ou características corporais e maneira como interage com as demais ${ }^{6}$. 


\section{Sexo biológico}

Compreende as características biológicas que a pessoa tem ao nascer e pode incluir cromossomos, genitália e composição hormonal ${ }^{6}$.

A abordagem qualificada sobre a identidade e as expressões de gênero, bem como a orientação sexual, no entanto, é bastante relevante para o cuidado em saúde de qualquer pessoa, e deve ser realizada de maneira clara e respeitosa, livre de julgamentos, discriminação, preconceitos e estigmas, garantindo a privacidade e confidencialidade das informações compartilhadas ${ }^{1}$.

Em relação à orientação sexual e às categorias identitárias de gênero, cabe ressaltar o que Hardt e Negri ${ }^{7}$ afirmam sobre os movimentos revolucionários alicerçados na identidade: "É este o enigma que enfrentamos: a política revolucionária precisa começar na identidade, mas não pode terminar nela”; deve-se buscar um mundo em que haverá a proliferação das singularidades. E, neste sentido, é essencial que os serviços e equipes de saúde estejam preparados para absorvê-las.

\section{COMO ORGANIZAR A ATENÇÃo EM SAÚDE BUCAL?}

As equipes de saúde bucal, uma vez atentas às necessidades específicas e diferenciadas das pessoas LGBTI+, são capazes de compreender melhor as causas e desenvolver respostas inovadoras àquelas demandas. Por outro lado, a discriminação pode resultar na recusa absoluta da prestação de cuidados, atenção de má qualidade e tratamento desrespeitoso ou abusivo, sobretudo a travestis e transexuais ${ }^{1,4}$.

Apesar da lacuna de informações sobre a saúde bucal da população LGBTI+, estudos na área de Psicologia junto a esses grupos revelaram o que se denominou como estresse de minorias, e agravos resultantes de vivências negativas em relação à própria orientação sexual e/ou identidade de gênero incidem frequentemente na saúde bucal ${ }^{6}$.

O conhecimento do processo de saúde e doença permite traçar correlações entre o uso abusivo de álcool, cigarro e outras drogas como fatores de risco para o desenvolvimento do câncer de boca; crises depressivas podem prejudicar os cuidados de higiene bucal; além disso, certos antidepressivos apresentam efeitos colaterais como hiperplasia gengival e xerostomia; os transtornos de ansiedade e a bulimia podem levar ao desgaste no esmalte dentário, lesões de mucosas e, mais além, ao risco de bruxismo 6 .

Em busca de mudanças corporais que expressem sua identidade de gênero, pessoas trans podem recorrer ao uso de hormônios, prescritos por profissionais ou utilizados por automedicação, e por isso há que se imaginar todas as consequências fisiológicas do uso destes fármacos. Por fim, é importante que a Odontologia possa lançar mão da possibilidade de realização de alguns procedimentos para a harmonização orofacial; além da reabilitação dentária e tratamentos ortodônticos, que podem auxiliar no aumento da autoconfiança e autoestima dos pacientes ${ }^{6}$.

O Manual intitulado: a saúde bucal no Sistema Único de Saúde ${ }^{2}$ posiciona que o processo de trabalho das equipes de saúde bucal deve levar em consideração a luta pelos direitos de cidadania e direitos da população de Lésbicas, Gays, Bissexuais, Trans e Intersex (LGBTI+) que integram o rol de atividades voltadas à promoção da qualidade de vida desta comunidade. 


\section{COMO GARANTIR ACOLHIMENTO E DIREITOS NO COTIDIANO DOS SERVIÇOS DE SAÚDE?}

Comecemos pelo respeito ao nome social, que é aquele através do qual pessoas transgênero - travestis, mulheres e homens trans, gêneros não binários e outros - identificam-se, são ou desejam ser socialmente reconhecidas. A atenção e o respeito ao nome escolhido por pessoas em transição ou afirmação do gênero autopercebido é uma das condutas com maior impacto positivo: a literatura aponta para a diminuição do sofrimento psíquico, de sintomas depressivos e suicídio, ao mesmo tempo em que aumenta a percepção de pertencimento social e autoestima ${ }^{6}$.

A identificação pelo nome social em todos os documentos dos usuários do sistema se saúde, o que inclui o cartão SUS, é um direito garantido desde 2009 pela Carta de Direitos dos Usuários do SUS, estabelecida pela Portaria 1.820 de 13 de agosto de 2009; além disso, o nome social é garantido pelo Decreto Presidencial 8.727/2016.

O uso do nome social surge como ferramenta para promoção do acesso das pessoas transexuais e travestis aos serviços de saúde, favorecendo o acolhimento por parte dos profissionais e o estabelecimento do vínculo profissional-paciente, binômio importantíssimo no que se refere à permanência do usuário no serviço e à aderência aos cuidados em saúde ${ }^{8}$.

Esse texto, que toma por base a concepção ampliada de saúde ${ }^{9}$ o o cuidado centrado na pessoa, sugere a urgência na adoção de estratégias que recomponham a relação singular entre profissional e usuário, capazes de promover equidade, reduzir as desigualdades nos serviços de saúde bucal, fortalecer os direitos da população LGBTI+ e garantir o acolhimento e a atenção integral à saúde por parte das equipes de saúde bucal.

Os profissionais de saúde bucal devem garantir tratamento igualitário para as pessoas e fomentar abordagens de saúde sem discriminação ou estigmatização. É urgente que o respeito aos direitos humanos, incluindo gênero e orientação sexual, sejam tomados como componentes fundamentais do processo de trabalho das equipes de saúde bucal e para o cuidado em saúde sem preconceito.

\section{REFERÊNCIAS}

1. Brasil. Ministério da Saúde. Secretaria de Gestão Estratégica e Participativa. Departamento de Apoio à Gestão Participativa. Política nacional de saúde integral de lésbicas, gays, bissexuais, travestis e transexuais. 1. ed. Brasília: Ministério da Saúde; 2013.

2. Brasil. Ministério da Saúde. Secretaria de Atenção à Saúde. Departamento de Atenção Básica. A saúde bucal no Sistema Único de Saúde. Brasília: Ministério da Saúde; 2018.

3. Mendes EV. As redes de atenção à saúde. Brasília: Organização Pan-Americana da Saúde; 2011.

4. Russell S, More F. Addressing health disparities via coordination of care and interprofessional education: lesbian, gay, bisexual, and transgender health and oral health care. Dent Clin North Am. 2016;60(4):891-906.

5. Nações Unidas. Nascidos livres e iguais: orientação sexual e identidade de gênero no regime internacional de direitos humanos. Brasília; 2013.

6. Educação, saúde e diversidade: dicas para boas práticas em saúde bucal. Porto Alegre: UFRCS; 2020.

7. Hardt M, Negri A. Bem-estar comum. Record; 2016.

8. Silva LKM, Silva ALMA, Coelho AA, Martiniano CS. Uso do nome social no sistema único de saúde: elementos para o debate sobre a assistência prestada a travestis e transexuais. Physis: Revista de Saúde Coletiva. 2017;27(3):835-46.

9. Campos CWS, Amaral MA. A clínica ampliada e compartilhada, a gestão democrática e redes de atenção como referenciais teórico-operacionais para a reforma do hospital. Ciênc. saúde coletiva. 2007;12(4):849-59. 